\title{
frontiers
}

FOR YOUNG MINDS
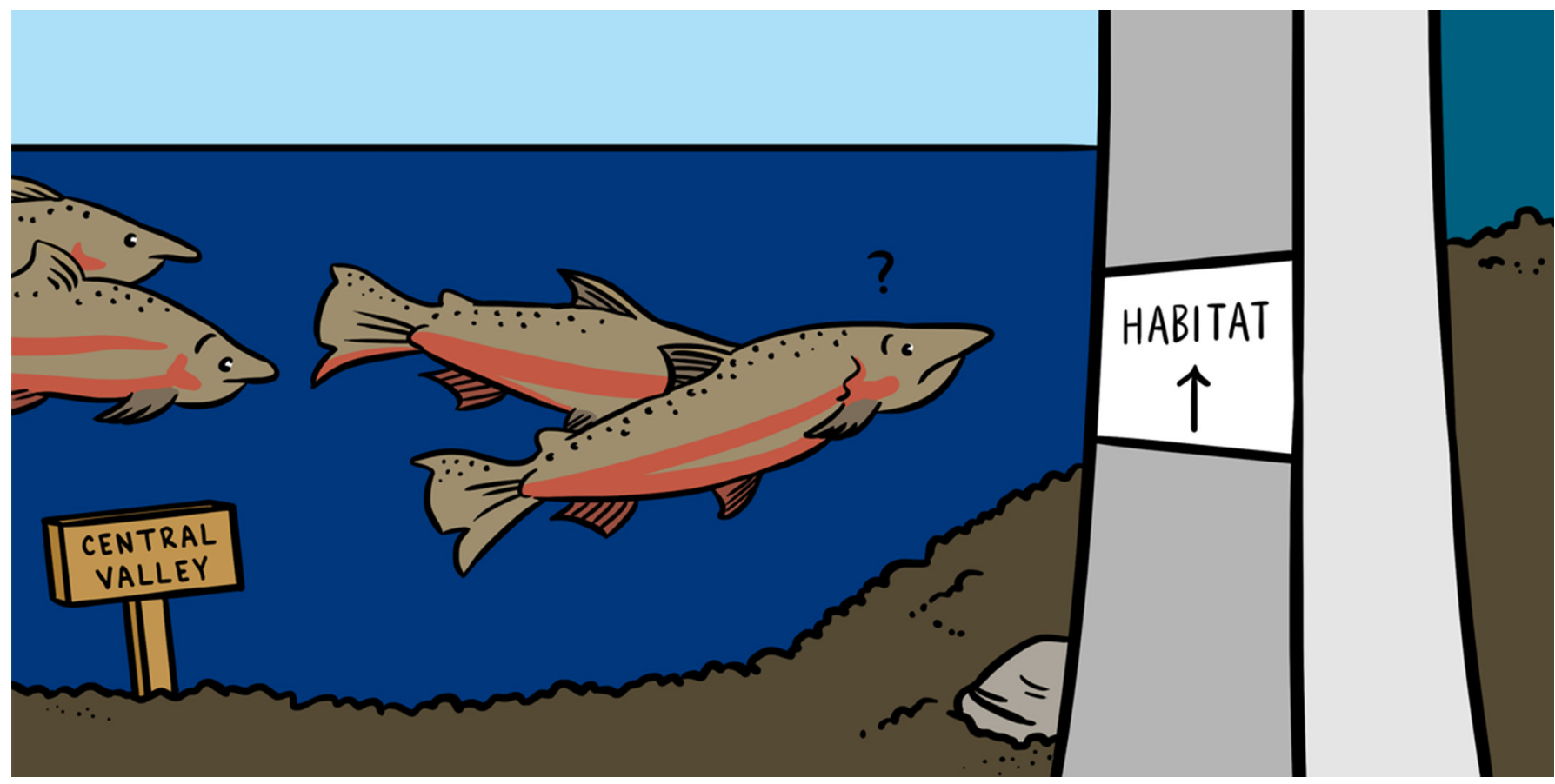

\section{THE CENTRAL VALLEY SALMONID STORY: SIX MILLION YEARS IN THE MAKING}

\section{Hilary Glenn *, Stacie Fejtek * and Jacob Rennert *}

California Central Valley Office, National Marine Fisheries Service, National Oceanic and Atmospheric Administration, Sacramento, CA, United States

YOUNG REVIEWER:

SIGNE

AGE: 10
For over six million years, salmon and steelhead (known as salmonids) have returned to the California Central Valley. After swimming under the Golden Gate Bridge and through the San Francisco Bay, adult salmonids swim hundreds of miles up the Sacramento or San Joaquin Rivers. Before dams were built, three out of the five salmonid species swam from the Central Valley into high-elevation, cold-water streams within the Sierra Nevada, southern Cascades, and Coastal Mountain ranges to finish their life cycles. Unfortunately, barriers such as dams cut-off salmonids from their home streams. When salmonid populations decrease, the effects are felt across the ecosystem-everything from microbes to humans feels the disconnection between the rivers and the ocean. Governmental agencies and their partners are teaming up to restore Central Valley salmonid populations by reconnecting them to their habitats and putting them back into high-elevation streams. 


\section{SALMONIDS}

A group of fish that spawn in fresh water and have adipose fins Some, like steelhead and salmon, live in the ocean as adults and migrate to the river to spawn.

\section{ANADROMOUS FISH}

Fish that are born in rivers (freshwater), then spend their adult lives in the ocean (saltwater), and then return to rivers to reproduce.

\section{RUN}

The time of year a salmonid travels from the ocean to the river. The Central Valley has four runs of salmon (winter, spring, fall, and late-fall) and one of steelhead.

\section{SPAWNING}

When a female fish releases her eggs into her rock nest (called a redd).

\section{SALMONIDS: A CONNECTION BETWEEN THE OCEAN AND THE MOUNTAINS}

Salmon and steelhead are two closely related fish that are complicated and fascinating. Together, they form a group called salmonids. Salmonids are anadromous fish, meaning they are born in rivers and then migrate hundreds of miles from rivers to the ocean and back again, almost to the exact spot they were born, to reproduce and then die. Salmonids are a connection between the ocean and the mountains. In California (United States), anadromous fish evolved to migrate through specific rivers along the Central Valley and during different seasons. The Central Valley is an unusual place to find a fish often found in the ocean because the water is very different from the water in the ocean. The complex life cycle of salmonids helps them survive these differences, but also exposes them to many threats that could lead to their extinction. Their extraordinary journey through diverse habitats makes these fish important to many different ecosystems throughout California. When given enough water and correct temperatures, salmonids have the ability to adapt and thrive in the rivers of the Central Valley [1]. Since the early 1900's California's Central Valley has changed so much that scientists are not sure how much longer salmonids will survive. But, if people act quickly, we can still help these important species survive and thrive once again.

\section{SALMONIDS EVOLVED WITH THE CALIFORNIA LANDSCAPE}

The Sacramento and San Joaquin Rivers in the California Central Valley may seem like strange places to find a fish that spends most of its life in the ocean, given the Central Valley's distance from the ocean and high temperatures during the summer months. Yet, salmonids have lived there for millions of years. When a particular group of salmonids migrates together from the ocean to freshwater, it is called a run. Each species' run occurs at a different time of the year, the same way some schools have different times for lunches so that the entire school is not using the cafeteria at the same time. Run timing divides Central Valley Chinook salmon into four special groups from which their names are based: fall-run, late fall-run, spring-run, and winter-run (Figure 1). The migration timing of the late-fall Chinook salmon run overlaps with that of Central Valley steelhead.

Adult fall-run salmon migrate into rivers during the fall when temperatures begin to drop. After migrating, they immediately begin building nests (also called redds) and spawning (laying eggs) in rivers at lower elevations on the Valley floor. Adult winter- and spring-run salmon migrate into the rivers in the Central Valley while temperatures are still cool. When these salmon spawn in the late spring and summer, their eggs and juveniles need to be in cooler water than is found in the rivers. They used to spawn in high-elevation mountain streams, where 
Figure 1

Run timing for salmonids in the Sacramento and San Joaquin Rivers in the California Central Valley. The direction of the fish shows whether they are swimming upstream (headed towards the right) or downstream (headed towards the left). All the adults (larger fish) swim upstream (saltwater to freshwater) while the juveniles (little fish) swim downstream (freshwater to saltwater). Yearlings (medium-sized fish) are juveniles that have spent extra time in freshwater for about a year, so they are really big when they migrate downstream.

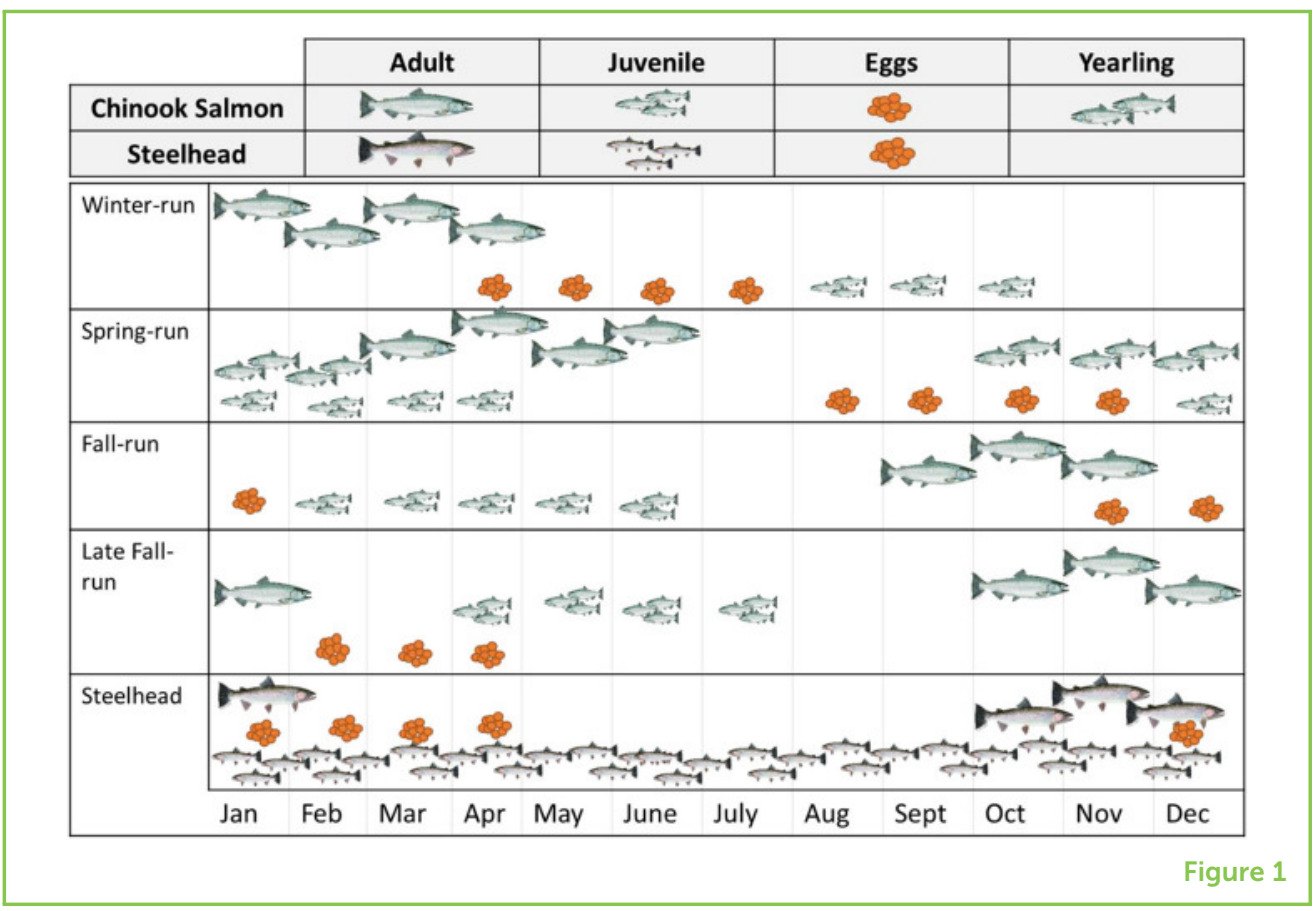

water is kept very cool and clean by melting snow. Access to many of these cool mountain streams was blocked by dams (Figure 2). So, now these salmon are trapped!

Winter-run must spawn in less preferred habitat downstream of a dam in the Sacramento River, while spring-run spawn in less than ideal habitats in either the Sacramento or San Joaquin Rivers. If these rivers become too hot during summer, winter-run and spring-run eggs will die. Unfortunately, this has already happened during the long drought of 2012-2016 Without access to naturally cold, high-elevation streams, winter- and spring-run salmon must depend on people to provide them with the cool, clean water they need to survive [2]. Today, winter- and spring-run salmon are less abundant than fall-run salmon because of the dams (Figure 2).

\section{SALMONIDS AT RISK OF EXTINCTION: FISH IN HOT WATER}

Salmon must use their natural instincts to navigate the rivers of the Central Valley that connect San Francisco Bay to mountain streams. The key for winter- and spring-run salmon to successfully complete their journey is the water produced by seasonal storms. Seasonal storms allow the rivers and streams to swell and fill their banks. This extra water helps fish get to areas that are out of reach during the dry season, because areas with boulders, steep waterfalls, or other obstacles are flooded allowing fish to migrate upstream. Without this stormwater, salmonids are trapped on the Valley floor where the water is too hot. Sadly, many of these fish die from the high temperatures 
Figure 2

Dams block winter-run and spring-run salmon from reaching the high-elevation mountain streams they evolved to live and spawn in. Currently, all the California Central Valley salmon runs must spawn in low-elevation rivers and streams (Image credit: Stephanie Littlebird Fogel).

\section{KEYSTONE SPECIES}

A species with a large effect on its ecosystem. The presence or absence of a keystone species affects all the creatures in the ecosystem.

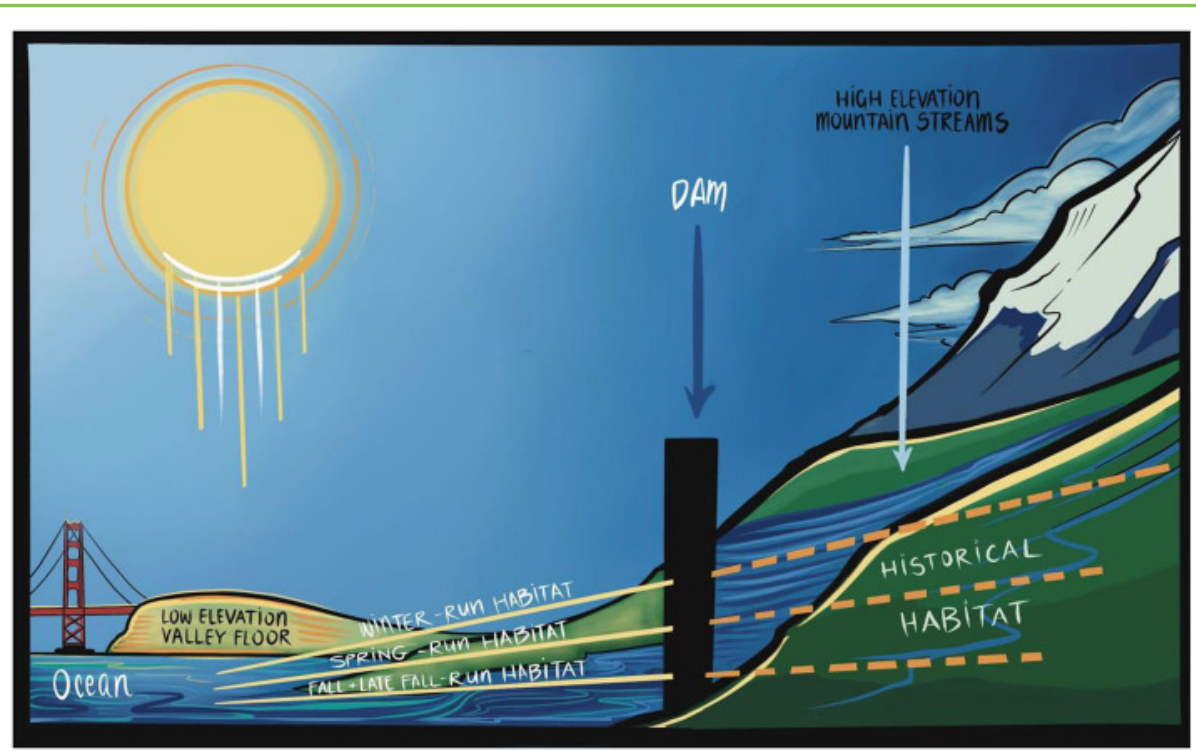

Figure 2

before they can return to and spawn in the mountain streams where they were born.

Dams control floods, create electricity, and store water for people living in cities and for crops. But they also block winter- and spring-run salmon and steelhead from reaching the habitats they need to survive [3]. Even a small dam, road crossing, or bridge can create an impassable barrier for a two-foot-long fish. Many dams include special passages for fish to swim up on their own, and sometimes scientists trap fish and move them past the dam in trucks full of water [2]. But the dams in the Central Valley currently do not have any way for fish to get around them, and they block about $90 \%$ of winter- and spring-run spawning habitat (Figure 3). As a result, these fish are limited to living only in habitats below dams, which puts their populations at risk of extinction [1].

Dams also negatively change the movement of water, gravel, and wood debris between the mountains and the Central Valley, which fish all depend on. Dams trap the seasonal storm water that helps signal salmonids to swim into the Valley from the ocean and prevent streams from swelling with water, taking away the salmonids' access to the high elevation habitats they once used to survive the hot summer temperatures.

\section{SALMONIDS ARE IMPORTANT FOR THE ENTIRE ECOSYSTEM}

From microbes to humans, at least 137 different species depend on salmon. Salmonids are a keystone species. Keystone species are like the glue on an art project-without them, the whole thing falls 
Figure 3

The blue lines represent the habitat that was previously available to salmonids in the California Central Valley. The black lines represent habitat that is now blocked by dams and unavailable to anadromous fish. Dams can alter downstream water flow and temperatures [1]. (Image credit: NOAA Fisheries web story).

\section{ENDANGERED \\ SPECIES}

A species at risk of extinction in the very near future. The Endangered Species Act is the law that gives threatened or endangered species and their habitats protections to conserve the species.

\section{THREATENED}

\section{SPECIES}

A species that is likely to become endangered in the foreseeable future (see endangered species).

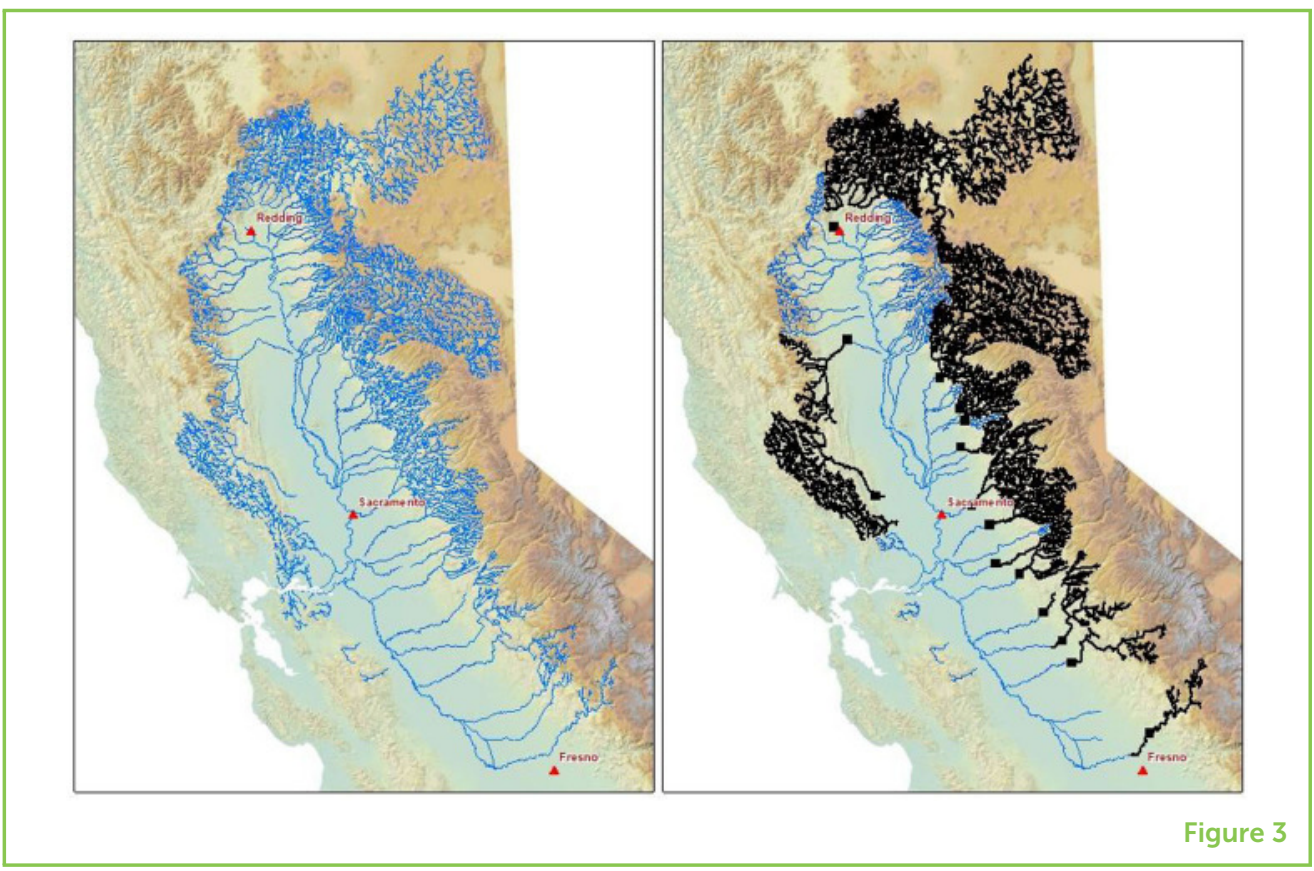

apart. An ecosystem will not survive without its keystone species. Salmonids link the rivers to the ocean by collecting ocean nutrients in their bodies as they eat and grow. They bring those nutrients with them when they return to the rivers to reproduce. Unlike salmon, which die after spawning, steelhead can return to spawn multiple times, delivering nutrients again and again. The dead bodies of adult salmonids release their ocean nutrients, enriching the habitats and food chains of the forests and mountains, the way fertilizer enriches a garden, improving soils and helping trees and plants near salmonid streams grow. Areas like the Central Valley have relied on salmonids to deliver these essential nutrients to the landscape for over six million years. Traditional/Indigenous cultures from the Central Valley recognized the role salmon play in the ecosystem and honor them through traditions, making salmon important to past and current residents in the Central Valley. Unfortunately, areas above Central Valley dams have been without those ocean nutrients for almost a century, putting the ecosystem at risk.

\section{HELPING THE SALMON STORY TO CONTINUE}

Millions of salmonids once swam through the Central Valley every year, on their journey from the ocean to the mountains. Now, only thousands return, and three of the five Central Valley runs are on the endangered species list. Winter-run Chinook salmon only exists in the California Central Valley and is one of the most endangered species in the United States, while spring-run Chinook salmon and steelhead are threatened. 


\section{RESILIENCE}

The capacity of an ecosystem or organism to respond or adapt to a disturbance by resisting damage and recovering quickly.
The National Oceanic and Atmospheric Administration's (NOAA) Fisheries branch of the government is working to conserve and manage coastal and marine ecosystems and resources in the United States. NOAA Fisheries established three criteria that salmonid populations must meet to recover and be taken off the endangered species list $[4,5]$. First, salmonid populations must be able to survive changes in annual rainfall caused by climate change. Too much or too little water can be fatal during the wrong time of the year. Second, enough adults must return and spawn each year to support the population of the next generation. Third, there must be multiple salmonid populations in different rivers and streams, so catastrophic events such as diseases or fires don't wipe out the entire species at once [4].

NOAA Fisheries and its partners are working to help Central Valley salmonid populations by finding new places for them to live, helping them move around dams, and looking for other ways to create resilience to climate change $[2,4]$. You can help, too! Salmonids can be supported through community efforts as simple as picking up trash, planting trees, capturing rainwater for your garden, or saving water during your shower. Our job at NOAA Fisheries is to help scientists and land managers find new ways to help salmonids return home. By bringing fish back to high-elevation streams that are naturally cooler and less populated, we will help these fish survive climate change. Creating resilience involves working together with the people of the Central Valley to use and share water in ways that work for everyone, including the fish. It is everyone's responsibility to reconnect these salmonids to the rivers and streams they spent six million years evolving to inhabit. Afterall, this is their home!

\section{REFERENCES}

1. National Oceanic and Atmospheric Administration. 2020. Salmon and Steelhead Habitat Loss in the Central Valley. Available online at:

https://noaa.maps.arcgis.com/apps/MapJournal/index.html?appid=ceebefd968 5143daa5bf30d5a7e0c7fa (accessed September 15, 2020).

2. National Oceanic and Atmospheric Administration. 2019. Reintroducing Fish Upstream of Rim Dams: Providing Passage to Advance Salmon Recovery in California's Central Valley: Frequently Asked Questions. Available online at: https://www.fisheries.noaa.gov/west-coast/endangered-species-conservation/ california-fishpassage-frequently-asked-questions (accessed September 15, 2020).

3. Moyle, P., Lusardi, R., and Samuel, P. 2017. SOS II: Fish in Hot Water. California Trout. Available online at: https://caltrout.org/sos (accessed September 15, 2020).

4. National Oceanic and Atmospheric Administration. 2014. Recovery Plan for the Evolutionarily Significant Units of Sacramento River Winter-Run Chinook Salmon and Central Valley Spring-Run Chinook Salmon and the DPS of California 
Central Valley Steelhead. Available online at:

https://www.fisheries.noaa.gov/resource/document/recovery-plan-

evolutionarily-significantunits-sacramento-river-winter-run (accessed

September 15, 2020).

5. National Oceanic and Atmospheric Administration. 2016. Species in the Spotlight: Priority Actions, 2016-2020. Sacramento River Winter-Run Chinook Salmon, Oncorhynchus tshawytscha. Available online at:

https://www.fisheries.noaa.gov/resource/document/species-spotlight-priorityactions-20162020-sacramento-river-winter-run-chinook (accessed September $15,2020)$.

SUBMITTED: 30 September 2020; ACCEPTED: 04 August 2021;

PUBLISHED ONLINE: 07 September 2021.

EDITED BY: Theodore M. Flynn, California Department of Water Resources, United States

CITATION: Glenn H, Fejtek S and Rennert J (2021) The Central Valley Salmonid Story: Six Million Years in the Making. Front. Young Minds 9:612814. doi: 10.3389/ frym.2021.612814

CONFLICT OF INTEREST: The authors declare that the research was conducted in the absence of any commercial or financial relationships that could be construed as a potential conflict of interest.

COPYRIGHT @ 2021 Glenn, Fejtek and Rennert. This is an open-access article distributed under the terms of the Creative Commons Attribution License (CC BY). The use, distribution or reproduction in other forums is permitted, provided the original author(s) and the copyright owner(s) are credited and that the original publication in this journal is cited, in accordance with accepted academic practice. No use, distribution or reproduction is permitted which does not comply with these terms.

\section{YOUNG REVIEWER}

\section{SIGNE, AGE: 10}

I live in California and love to learn in 5th grade. Science is my favorite subject and I like experimenting too. Some of my hobbies are dancing, singing, playing instruments, and cooking. My sister is Maya and my kitten is Mabel. I like to play with them both! Bowling is fun and brings me closer to my family. My favorite foods are brownies and vegetarian taco salads. When I grow up, I want to be an actress or teacher.

\section{AUTHORS}

\section{HILARY GLENN}

Hilary Glenn is a fisheries biologist for NOAA Fisheries. She is recovering threatened and endangered species through a large-scale restoration project on the San 


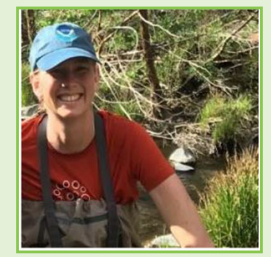

Joaquin River. She is an education and outreach coordinator and seeks to bring a salmon culture to the Central Valley of California through collaborative projects and partnerships. Hilary graduated from the University of California at Santa Cruz with a B.S. in marine biology and Louisiana State University with an M.S. in oceanography. Hilary has also spent time teaching SCUBA, doing research on coral reefs, and working as an observer on fishing boats in Alaska. *hilary.glenn@ anoaa.gov

\section{STACIE FEJTEK}

Stacie Fejtek (Smith) currently works in the Central Valley with NOAA Fisheries West Coast Region on hydropower projects and reintroductions of salmonids to help with the recovery of endangered and threatened fish species. Stacie focuses on using interdisciplinary and network-based management strategies for addressing issues from river headwaters to the ocean. Stacie's approach is rooted in a strong academic and scientific foundation with a B.S. in Aquatic Biology from the University of California Santa Barbara, a M.S. in biology from San Diego State University, and doctoral work at the University of California Los Angeles in the multidisciplinary Environmental Science and Engineering Program. *stacie.smithanoaa.gov

\section{JACOB RENNERT}

Jacob Rennert is a fisheries biologist for Lynker Technologies, working with NOAA Fisheries. He is working alongside the Federal Emergency Management Agency (FEMA) to improve projects responding to natural disasters such as wildfires and floods, to help endangered and threatened salmonids and sturgeon. He graduated from the University of North Carolina Wilmington with a B.S. in marine biology and the Florida Institute of Technology with an M.S. in marine biology. Jake participated in research projects investigating tarpon, bonefish, and snook life history in Florida, Cuba, and the Bahamas. He loves playing ice hockey, skiing, and fly-fishing. *jake.rennert@noaa.gov 